\title{
Local Languages and Character Building: A Study on the Contribution of Mother Tongue to the Formation of Human \\ Character
}

\author{
I. Ketut Warta \\ Institut Keguruan dan Ilmu Pendidikan (IKIP) Mataram, West Nusa Tenggara, Indonesia
}

\begin{abstract}
The research aims to examine how ancestor language contributed to character building and to explore some ways to protecting local languages from death. Questionnaires and an interview were used to gather information from students and teachers at Institut Keguruan dan Ilmu Pendidikan (IKIP) Mataram. Qualitative information also came from documents and some were derived from language theories. Analysis indicated that the formation of character education should consider local language as its component part; the cooperation of mother tongue into character education could be of assistance to preserving local languages from disappearance. The study was restricted to a small scale research and the analysis was developed within the context of IKIP Mataram. The findings would help to have a better understanding of the significance of mother tongue in character formation, to recommend character education as model of future education. The study was originally based on the primary information and had never been sent for publication. The results could be of benefit to those who are of interest to research into teaching.
\end{abstract}

Keywords: mother tongue, character formation, human character

\section{Introduction}

Research on mother tongue and character education have been widely performed and presented to support the claim that local languages, in this report mother tongue, is in the state of serious danger. However, a study focusing on the importance of mother tongue in character building is still limited in number. Human character, education, and mother tongue have recently been serious debates in this country, Indonesia. The question of mother tongue has also been hot issue today. The issue has been widespread; it is no longer local or national, but it has been worldwide issue. This is the fact that current condition shows disharmonious relationship among human; conflict is everywhere. Education is characterized as being highly pragmatic oriented. It emphasizes more on the cognitive aspect rather than the affective. Knowledge is necessary, but without wisdom, it may endanger the future life of human beings (Warta, 2012, pp. 17-20). All these reality are in the face of serious problem and they need urgent alternatives. This report on local languages and character building, an examination on the contribution of mother tongue to the formation of human character, is a quantitative research carried out at public education in Mataram, West Nusa Tenggara, Indonesia. The purpose of the research is to explore how mother tongues should be preserved from extinction and the role of local languages played in the construction of character formation. On the basis of the present conditions, analysis, and

I. Ketut Warta, Dr., senior lecturer, Institut Keguruan dan Ilmu Pendidikan (IKIP) Mataram, West Nusa Tenggara, Indonesia. 
description of earlier studies, the author hypothesizes that: (1) The implementation of Bahasa Indonesia (Indonesian National Language) as medium of instruction has significantly contributed to the extinction of local languages; (2) mother tongue, the best medium for the expression of one's ideas and feelings, language of social group formation, medium of acquiring local knowledge and culture, creative self-expression, instrument of emotional development, of growth, and source of original ideas has very great importance in the formation of human character (see http://www.unesco.org/new/File).

\section{Method}

The quantitative design was carried out to find local languages and character building, and the contribution of mother tongue to the formation of human character. The study uses information collected from primary and secondary sources. Quantitative information was collected by means of questionnaire. The questionnaire was distributed to the sample of primary sources teachers, students and principles, students and lectures, and researchers. An interview to educators was also conducted in order to get additional information and justification. This qualitative information was interpreted and analyzed using content analysis. Analysis on quantitative data, data presentation, and statistical model of analysis are displayed in Table 1 that follows. It is worth noting that the term mother tongue in the present study may refer and appear in different names. It may stand for first language, one native speaker, language of the heart, ancestor language, and parent language. Some linguists prefer to use the names vernacular, local language, language of local wisdom, indigenous language, home language, and language of ethnicity, etc.

\section{Findings}

This study is an attempt to analyze local languages and character building, the contribution of mother tongue to the formation of human character. Quantitative data collected by means of questionnaires were analyzed by percentages; qualitative data collected from documents, interview, and library were analyzed by means of contents analysis. Table 1 displays the quantitative data, statistical model of analysis, and findings of the research. Interpretation on the findings is intended to make the research findings to be meaningful.

Table 1

Data Display and Analysis of Quantitative Data

\begin{tabular}{lllll}
\hline Constructs & $\mathrm{T}(N=20)$ & $\mathrm{P}(N=20)$ & $\mathrm{R}(N=20)$ & $\mathrm{E}(N=20)$ \\
& $\mathrm{N}(\%)$ & $\mathrm{N}(\%)$ & $\mathrm{N}(\%)$ & $1 \%)$ \\
\hline \multirow{3}{*}{ 1. BI and medium of instruction } & $19(95 \%)$ & $17(85 \%)$ & $18(90)$ & $16(80 \%)$ \\
& $1(5 \%)$ & $3(15 \%)$ & $2(10 \%)$ & $4(20 \%)$ \\
& $20(100 \%)$ & $20(100 \%)$ & $20(100 \%)$ & $20(100 \%)$ \\
2. The power of MT & $19(95 \%)$ & $17(85 \%)$ & $18(90 \%)$ & $16(80 \%)$ \\
& $1(5 \%)$ & $3(15 \%)$ & $2(10 \%)$ & $3(15 \%)$ \\
3. Nature and MT & $20(100 \%)$ & $20(100 \%)$ & $20(100 \%)$ & $19(95 \%)$ \\
& $16(80 \%)$ & $12(60 \%)$ & $18(90 \%)$ & $17(85 \%)$ \\
4. MT and ethical behavior & $4(20 \%)$ & $5(25 \%)$ & $2(10 \%)$ & $3(15 \%)$ \\
& $20(100 \%)$ & $17(85 \%)$ & $20(100 \%)$ & $20(100 \%)$ \\
& $18(90 \%)$ & $16(80 \%)$ & $17(85 \%)$ & $19(95 \%)$ \\
5. MT and medium of instruction & $2(10 \%)$ & $3(15 \%)$ & $3(15 \%)$ & $1(5 \%)$ \\
& $20(100 \%)$ & $19(95 \%)$ & $20(100 \%)$ & $20(100 \%)$ \\
& $20(100 \%)$ & $19(95 \%)$ & $17(85 \%)$ & $16(80 \%)$ \\
& $0(0 \%)$ & $1(5 \%)$ & $3(15 \%)$ & $4(20 \%)$ \\
\end{tabular}


(table 1 continued)

\begin{tabular}{lllll}
\hline Constructs & $\mathrm{T}(N=20)$ & $\mathrm{P}(N=20)$ & $\mathrm{R}(N=20)$ & $\mathrm{E}(N=20)$ \\
& $\mathrm{N}(\%)$ & $\mathrm{N}(\%)$ & $\mathrm{N}(\%)$ & $\mathrm{N}(\%)$ \\
\hline \multirow{2}{*}{ 6. Human character } & $16(80 \%)$ & $15(75 \%)$ & $17(85 \%)$ & $20(100 \%)$ \\
& $4(20 \%)$ & $5(25 \%)$ & $3(15 \%)$ & $0(0 \%)$ \\
& $20(100 \%)$ & $20(100 \%)$ & $20(100 \%)$ & $20(100 \%)$ \\
7. Child and nature & $19(95 \%)$ & $18(90 \%)$ & $19(95 \%)$ & $20(100 \%)$ \\
& $1(5 \%)$ & $2(10 \%)$ & $1(5 \%)$ & $0(0 \%)$ \\
8. Pupils as centre of the world & $20(100 \%)$ & $20(100 \%)$ & $20(100 \%)$ & $20(100 \%)$ \\
& $14(70 \%)$ & $12(60 \%)$ & $15(75 \%)$ & $17(85 \%)$ \\
9. Good life to live & $6(30 \%)$ & $5(25 \%)$ & $5(25 \%)$ & $3(15 \%)$ \\
& $20(100 \%)$ & $17(85 \%)$ & $20(100 \%)$ & $20(100 \%)$ \\
& $19(95 \%)$ & $17(85 \%)$ & $19(95 \%)$ & $19(95 \%)$ \\
& $1(5 \%)$ & $3(15 \%)$ & $1(5 \%)$ & $1(5 \%)$ \\
\hline
\end{tabular}

Notes. $\mathrm{T}=$ teacher; $\mathrm{P}=$ pupils; $\mathrm{R}=$ researcher; $\mathrm{E}=$ educators.

\section{Discussions}

1. The implementation of Bahasa Indonesia (Indonesian language) as medium of instruction has significantly contributed to the extinction of local languages. If this claim is true, as it is stated by Hamadi, (2007) and Lauder (2009), then we can make a prediction that the inclusion of local languages or mother tongues in curriculum and their use as language of instruction in education can help protect them from being extinct. Questionnaires addressed to 20 teachers shows that 19 (95\%) out of 20 says that Indonesian language, the national and formal language of the government, is the trigger of the extinction of mother tongue; while pupils, researchers, and educators say the same thing, that is 17 ((85\%), 18 (90\%), and 16 (80\%) respectively. From this very empirical study, it is safe and sound to claim that mother tongue in order to be peacefully alive should replace the position of Indonesian as medium of instruction (Jazadi, 2008). Put it another way, the government through the Ministry of Research, Science, and Technology of Higher Education should consider the possibility of local languages to be inclusive in the curriculum.

2. There is a belief in the sphere of language study that language is powerful. Indigenous languages, as they are believed, have the control over their native speakers. Balinese, Sasaknese, and other local language, for example, have the strength to control, build, and direct their speakers' characters. No other language has the power to change the speaker's mind except, that of parent language. The acquisition of mother tongue by a child has been considered basic in the development of perception and concept of the world. The child's world view was first developed when he/she first acquired his/her mother tongue. Through home language, parent can touch the children hearts and direct the children behavior (see http://esl.fis.edu/parents/advice/intro-P/htm, accessed 20 July 2013). It is through the first language that the child recognizes his/her environment, including understand perceive the world. This claim proved true if it confirmed with the survey as it is presented in Table 1. Of 20 teachers, 19 (95\%) agree with the statement; 17 (85\%) out of 20 pupils say the same; 18 (90\%) out of 20 researchers, and 16 (8\%) educators are of the same opinion.

3. The world and first language are connected; and the link is direct. Our concept of the world is symbolically referring to the object we perceive. Our world view, concept formation of things, names, names and reference are, mostly if not all, expressed in the language of ancestor (Mulyani, 2010). Finding shows 16 (80\%) teachers, 12 (60\%) pupils, 18 (90\%) researchers, and 17 (85\%) educators. Put it another way, on the average, 15 (75\%) of the respondents agree that the world we live is better expressed by our mother tongue. 
That language is the expression of the world is empirically justified true. And that one native language can even be a better expression.

4. Indigenous language and the way their native speakers behave are inseparable; they are two in one. We easily identify one's origin by its very specific ways of living, like its tradition, culture, and the language they speak. Language of the heart which they proudly speak in their daily life has long been considered to represent who they are. Language of such kind is the art of giving instructions or training by which people learn to develop their mental, moral, and physical power to face challenges of life. No doubt, first language in education is essential and vital for a good and civilized life. And this is also a fact that education can be received by using any language; mother tongue is of no exception. If we are to respect world culture, we are to respect our local culture and to accept global culture is to accept the local culture. One cannot accept global culture by rejecting the local culture. The statement that mother tongue and ethical behavior is built in the first language one speaks and acquired through mother tongue proved true when confirmed with the empirical study. On the average, 18 (90\%) respondents agree with the claim (Bhushan, 2010). Briefly, indigenous language is a better means to expressing local culture and forming one behavior.

5. First language and language of instruction are primarily crucial in the context of acquiring our knowledge of the world. Knowledge in particular that of the local color, religious, cultural events, tradition, is impossible without local language. Training in the use of ancestor language, therefore, becomes the first important schooling and instrument of human culture. It is, therefore, tremendous to use mother tongue as medium of instruction in order to get a firm grounding in their mother tongue. Analysis results that on the average, 18.75 (93.75\%) of the respondents claim that first language should be the language of instruction. It is believed that the formation of human character is made possible only by this very ancestor language. As a language of the heart, mother tongue can touch and go deeper to the spirit of the child and pupils when they are involved in communication.

6. By human character, we understand as one's specific ways of living; it covers among other things, its tradition, culture, mentality, morality, literature, especially the works of fiction, e.g., folklore. Folklore is reach of teaching, the teaching of moral, education, good conduct, and good life to live. They are all found in this type of traditional and oral fiction. Similarly, one should have the ability to read mother tongue because all such kind of traditional fictions use local languages as their instrument of expression. If we confirm the claim with the study, where on the average, 17 (85\%) of the respondents agree with the statement that human character is embodied or/and acquired in the language individual first learned. A full understanding of moral teaching, local wisdom, and culture can be achieved only in our own mother tongue. The fact that many, if not all, great authors or writers who are involved in fictions or literary writing are those who are native speakers of their language. Or to put it another way, great literatures are produced only in one' mother tongue, first language, native language, etc. It is hard, if not impossible, to find non-native speakers of English to write fictions in English. Most, if not all, authors of English literatures are native speakers of English.

7. Child and nature cannot be considered in isolation. Home language the child speaks is a social practice within social life, one practice among others, and inseparable from its environment, nature. It claims that child and nature are like a coin with two sides; each side depends on the other. Child without nature is nothing and so is the reverse. From this statement, we can propose that concept formation of the world and surrounding is basically derived from our first language. This is true as indicated by the finding that 19 (95\%) respondents 
support the claim. Man, as it is claimed, is the center of the world. Because the whole world works together in the service of man; and there is nothing from which he does not derive use and fruit in so much that all things seem to going about man's business and their own. Man is not only the lord of creation, but also its principle of order (see http://grammar.about.com/old/c/g/communicaterm.htm, accessed 30 July 2013).

8. Pupils as centre of the world suggest that the learning of mother tongue is of great significance; local culture, tradition, and literature can be better learned in the mother tongue. If by definition, mother tongue is language first acquired from mother; it is safe to say that pupils have the ability to develop their full understanding of their local culture, tradition, and surely full language proficiency. This claim justified when confirmed with the survey that 14.5 (72.5\%) on the average agree. It seems that this finding (8) and discussion to be paradox; learning and acquisition are two different things. Learning is to second or third or foreign language, while acquisition is for first language. We say, therefore, a child acquires her first language (first language acquisition) and a student learns her second/foreign language (second/foreign language leaning).

9. Good life to live is the end of education; this claim of wisdom is strongly believed rooted at the mother tongue. We learn a lot of local wisdom, culture, tradition, and literature from our local language. That is the fact that no one can deny. Refusal to reality is to ignore the tremendous contribution of the mother tongue in forming and building human character. The formation of human character is a must and it should be rooted from local wisdom, or we will lose our identity. Really, character built on the basis local knowledge is of great significance for the future life of human being, including future education. Character, humanity, and moral are very basic in all aspect of human life; they are imperative. Education, science, and business without those aspects are good for nothing, even dangerous to humanity. Result of the data analysis shows that 19 (95\%) out of 20 teachers agree with the statement; 17 (85\%) pupils are of the same response; and 19 (95\%) researchers and educators have the same opinion. On the average, 18.5 (92.5\%) respondents support the claim to be true.

\section{Conclusion and Suggestion}

In this modern world of highly technology and globalization, where life is highly materialistic and pragmatic oriented, the study of local languages or mother tongue and human character formation is surely of great importance. It is a necessity. The study would help us not only to protect our local cultures from foreign cultures but would also make us aware of the varied meaningful aspects of a good life to live. The study is a small-scale research and the analysis is developed within the context of IKIP Mataram. It is, therefore, highly suggested that a study of similar topic, but view from different perspective, is imperative. Educators, teachers, practitioners, academicians, and local government should take into serious consideration the inclusion of local languages in curriculum.

\section{References}

Bhushan, R. (2010). Mother tongue: The neglected resource for English language teaching and learning. Retrieved from http://www.langugeinindia.com

Chetia, K. (2012). Ethics and morality, a key factor of employee satisfaction and motivation: A study on the tea industries of upper Assam with special reference to Cinnamora, Gotonga and Teok Tea Estates. Paper presented in International Seminar on Ethics, Spirituality and Morality, January 3-4, New Delhi.

Hamadi, H. R. (2007). The Jakarta Post. Retrieved from https://www.thejakartapost.com/

Jazadi, I. (2008). The politics of curriculum. Mataram: NTB Press.

Lauder, M. (2009). The Jakarta Post. Retrieved from https://www.thejakartapost.com/ 
Mulyani, S. (2010). Understanding traditional expressions as Javanese local wisdom in generating societal harmony. Paper Presented in International Conference and Rancagé Award 2010, May 29, Auditorium of Yogyakarta State University.

Warta, I. K. (2012). Character education: Is education value free or bo und? Research Pool, An Interdisciplinary Journal, 2(1), $17-20$. 